\title{
Editorial:
}

\section{'Internationalising' Japanese Education: Contradictions, Challenges and Opportunities}

\author{
Edward Vickers ${ }^{*}$ \\ Special Editor
}

In the educational field in Japan today, the jargon of 'internationalisation' is everywhere. Several contributors to the current issue work at 'top global universities' (スーパー・グロ ーバル・大学), so designated by the Ministry of Education, Culture, Science and Sport (MEXT). There, we are exhorted to generate 'global human resources' (グローバル人材), use more English, send our students on overseas exchanges, publish in international journals, and compete in the global university rankings. But internationalisation begins much earlier than college. My son attended a private kindergarten whose declared mission was to nurture 'global citizens'; his public primary school trumpets its exchanges with overseas visitors, with posters illustrating how pupils 'introduced Japanese culture' to their foreign counterparts. Meanwhile, the government has recently announced plans to begin foreign language (i.e. English) lessons from Primary Grade 3. Viewed from the perspective of its educational institutions, then, this would appear to be a society animated by a growing openness to the wider world, and intent on preparing its young people to engage with it.

Or perhaps not. As the papers in this issue reveal, behind the jargon lies profound confusion over what 'internationalisation' means, why (or even whether) it matters, who it is for, and with whom it should engage. Should it aim primarily at engagement with the Anglophone West and English-speaking global elites? Or should it prioritise relations with Japan's East Asian neighbours and the integration of Japanese-resident Asian diaspora communities? Does it primarily involve raising a new generation of fluent English-speaking Japanese? Or should it mean fostering greater awareness and understanding of Asia, and the competencies required to deal with Asian societies? How should the incorporation of an 'international' element into the curriculum be related to learning about what it means to be Japanese? Most fundamentally, should 'internationalisation' be viewed instrumentally as a tool for maximizing national competitiveness, or as an exercise in broadening horizons and challenging ingrained assumptions that is intrinsically worthwhile in itself?

Many of these questions are barely addressed in mainstream public debate - although, as Okano and Tsuneyoshi show here, they often preoccupy educational practitioners, especially those dealing with migrant and minority groups. Instead, much discussion revolves around a presumed zero-sum equation that pits preservation of a Japanese cultural essence against engagement with the outside world. For many on the ascendant political right, the latter may be economically necessary, but should be confined within strictly policed parameters if Ja-

\footnotetext{
* Kyushu University e-mail: edvickers08@googlemail.com
} 
pan's precious uniqueness is to be preserved.

It is precisely this sort of zero-sum equation, and the narrow, exclusionary brand of nationalism that underpins it, that Rappleye critiques in his paper here. In doing so, however, he argues not for Japan to simply fall into line with some uniform template of global cosmopolitanism, but for a reconceptualisation of 'Japanese-ness' itself. Rejecting stale, conservative notions of tradition associated with nihonjinron, he sees 'Japanese-ness' as a 'foothold between... local essentialism and universal convergence'. For Rappleye, the importance of establishing or preserving such a 'foothold' derives largely from the looming threat of a 'hegemonic' or neo-colonial 'West', and the flattened, uniform brand of global culture it seeks to propagate. The reality of this threat, he argues, is apparent from the increasing dominance, in international education policymaking discourse, of a narrow focus on instruments (such as the OECD's PISA tests) for ranking educational 'performance.'

But to what extent does this discourse originate in 'the West', let alone represent 'Western' culture in all its diversity? There are significant divisions amongst (and within) 'Western' societies, often overlooked in America-obsessed East Asia, over visions of education and much else. Amongst prosperous, 'developed' societies, one key divide is arguably between an increasingly neoliberal 'Anglosphere' and East Asia on the one hand, and the more resolutely social-democratic societies of north-western Europe on the other. Meanwhile, if we consider questions of agency, key actors in China, India and other non-Western societies (including Japan) have played an important role in boosting and helping to shape the dominant, narrowly economistic global conversation on educational 'performance' - not simply because they have been brainwashed by a malevolent, all-conquering 'West', but for reasons of their own. This is a debate that does not simply pit 'the West' against 'non-Western' societies such as Japan, but cuts across such totalising national or civilizational categories. The results can include weird hybrids of globalized neoliberalism and nationalist essentialism - as evidenced by Arai's analysis, in The Strange Child, of 'the politics of patriotism in recessionary Japan' (reviewed here by O’Dwyer).

By contrast, Rappleye's own vision of 'Japanese-ness' is of a space for debate over education (and other public goods) that is rooted in an awareness of, and attachment to Japan's distinct social and cultural environment. This is all well and good, but we can and should go further, embracing a conception of identities that is layered rather than binary, in which 'Japanese-ness' exists not merely as an embattled national space preserving diversity from a putative 'Western' onslaught, but as one dimension of identity among several. For inhabitants of Japan, these layers or dimensions should, surely, include a consciousness of 'East Asianness' as an intermediary space between the 'Japanese' and the 'global'. Indeed, one of the most troubling features of current debate over educational internationalisation is the almost total lack of attention to this dimension.

Such a concept of 'layering' is a key theme of Sevilla's paper, which draws on the ideas of the eminent - and controversial - 20th-century philosopher, Watsuji Tetsuro. Public policy debate too seldom involves serious reflection on what - beyond the pursuit of economic growth and and national aggrandisement - educational internationalisation (or, indeed, education as such) is actually for. Sevilla sets out to address precisely such neglected or taken-for-granted ethical issues. His interpretation of Watsuji involves a nuanced critique of both ethical universalism - with its underlying vision of autonomous, but essentially identical, individual moral actors - and moral relativism. 'While there is a universal core to all morali- 
ty,' he argues, 'that core is never expressed independent of culture.'

Sevilla articulates a vision of morality that sees it not as a catechism of ethical absolutes, but as the negotiated product of a constant tension between the assertion of individual identity on the one hand, and the demands of community on the other. The space within which this negotiation takes place is captured, for him, by Watsuji's concept of 'emptiness'. Moral discourse is therefore at once fundamentally relational and rooted in the conditions of particular communities, but also dynamic and subject to constant change. History teaches us that cultures and the ethical norms that underpin them are fluid and evolving, and that their transformation is driven both by internal debate and external influence.

In discussing the implications of this vision for education, Sevilla argues that 'education for international understanding' (kokusai rikai kyouiku), as practised in Japan, needs to go beyond gawping at exotic customs on the one hand, and unreflective moral absolutism on the other. Referring to his own classroom experience, he stresses the importance of exposing students to cultural differences that they may find disturbing or worse, and challenging them to debate and engage with these in a way that prompts them to re-examine their own ethical assumptions. Only then, he contends, can we hope to get close to a real understanding of cultural difference in all its profundity and complexity.

However, policy in Japan today on internationalising education is far from embracing this sort of vision - as Okano and Ota demonstrate in their papers here. Indeed, interest in promoting real engagement with cultural difference seems weakest, Okano suggests, precisely in the elite institutions of higher education where scope for it might be assumed to be greatest. Exhortations to universities to engage with 'world-leading' (primarily Anglophone) institutions and prepare graduates for the 'globalised workplace' are, she observes, narrowly 'instrumentalist,' and do not prioritise 'intrinsic human development and the pursuit of knowledge'. Special funding and support for 'internationalisation' has been largely restricted to elite institutions, where it is coupled with a push to generate the talent perceived as necessary to drive technological innovation and economic growth. At the level of higher education, Okano finds little acknowledgement of the importance of engaging with domestic diversity and human rights education - except at some private universities in especially diverse areas. Instead, there is an emphasis on promoting 'international understanding' (mediated through English) and 'competitiveness' ('global human resources'), or on what Ota terms 'inward-facing internationalisation,' undertaken to enhance an institution's position vis-à-vis its domestic rivals.

At school and local government levels, however, the situation depicted by Okano is in some respects a mirror-image of that in elite universities. Closer to the educational 'grass roots,' there is often a greater emphasis on human rights education (targeted at longstanding minorities) and education for 'domestic internationalisation.' This is prompted by the very practical challenge of integrating returnees and diaspora communities - originally mainly Koreans and Chinese from Japan's former colonies, more recently Brazilians and others.

In contrast to the situation at tertiary level, talk of 'global human resources' is, Okano notes, 'rarely mentioned at the school level'. As Shimauchi also suggests in her paper here, the relatively impoverished vision of 'internationalisation' at university level is closely tied to narrowly instrumentalist national policy goals. At the level of compulsory schooling, by contrast, especially in areas of high diversity, understandings of 'internationalisation' have evolved towards a greater emphasis on 'multicultural symbiosis', in response to the needs of 
increasingly diverse local communities.

But what of the crucial high school level, about which the papers in this issue say relatively little? This is arguably where these different visions of 'internationalisation' clash, with the instrumentalist focus on 'global human resources' dominant at elite universities creating a narrowing backwash effect. This is especially apparent in the overwhelming focus on the teaching of English, to the virtual exclusion of Asian foreign languages such as Chinese and Korean - which, as it happens, are also the languages most widely spoken by minority ethnic-linguistic communities in Japan.

It is this absence or lack that Tsuneyoshi pinpoints in her critique of an approach that she dubs 'international' without being 'multicultural.' Focusing on primary schooling, she highlights the disjuncture between the ostensibly inclusive framing of 'foreign language activities' in official curricula, and the identification of these, in practice, solely with English. As she acknowledges, emphasis on English language education is not unusual internationally, but what is peculiar about Japan is the way in which 'foreign' is equated with 'English' in policy rhetoric and media coverage. Related perceptions of Western (i.e. Anglophone) linguistic 'imperialism' help account for confused and half-hearted promotion of English, even while the equation of 'foreignness' with English competence fuels what Tsuneyoshi politely terms 'un-multicultural' behaviour towards foreigners. Most students thus remain unable to communicate meaningfully in any foreign language, and hold an image of 'foreigners' that bears no relation to the kinds of inter-cultural interactions that are in fact most likely to occur in Japan.

The groups marginalized by the exclusive focus on English include ethnic Koreans and Chinese, who together account for around $50 \%$ of the foreign resident population, as well as Brazilians, Southeast Asians and indigenous minorities (Ainu, Okinawans, burakumin). Tsuneyoshi discusses the insidious effects of a mindset that often 'evaluates visitors to the Japanese classroom based on their level of spoken English, glossing over issues related to Japan's colonial history or the power structure of our world.' In the process, she suggests, this obstructs or undermines the kind of cross-cultural interactions - with the country's closest neighbours and largest minority communities - that are most crucial to Japan's future. Indeed, those in Kawasaki (on the southern edge of Tokyo) who have sought to promote genuine multicultural interaction involving the local Korean community have been at pains to dissociate themselves from the officially-sponsored agenda of 'internationalisation', given its exclusive identification with English.

Tsuneyoshi acknowledges that the focus on English is understandable, up to a point, and notes how it is increasingly reinforced by public examinations and the growth of private schooling. But these societal trends - by no means exclusive to Japan - when reinforced by the narrow official discourse on 'internationalisation', determine that those who come into the Japanese classroom under the auspices of 'foreign language activities' tend to be drawn from a narrow range of linguistic and cultural backgrounds (as evidenced by the nationalities of most of those recruited as Assistant Language Teachers). And given the low level of English of most Japanese students (and teachers), the nature of the interactions that then take place are usually superficial at best - and of minimal significance for the promotion of inter-cultural understanding.

When it comes to 'internationalisation', then, the contradictions in official curricular discourse are acute. In contrast to many ethnic Koreans, Chinese and other Asians - often long- 
term residents - the 'foreigners' associated with the 'internationalisation-through-English' discourse are almost invariably depicted as temporary visitors to Japan. Tsuneyoshi highlights the disjuncture between exclusively English 'foreign language activities' and the typical portrayal of 'foreigners' in history and social studies texts, where issues of Japanese colonialism and historical discrimination against Koreans and Chinese are discussed. Ironically, even while drawing attention to such discrimination, the school curriculum effectively perpetuates it by ignoring or implicitly devaluing those communities' linguistic and cultural heritage. Recent official policy statements do call for greater recognition of the 'inter-cultural' experiences gained by (mostly prosperous, middle-class) Japanese youngsters returning from overseas, including through 'expanding the opportunities to learn Asian languages' (though so far with little practical effect). But the linguistic attributes of immigrant communities tend to be seen simply as a source of problems, to be resolved through provision of more effective Japanese language instruction.

In other words, official discourse on 'internationalisation' posits interaction between a 'Japan' implicitly construed as linguistically and culturally homogenous, and a predominately Anglophone 'foreign' world whose denizens come to Japan only as temporary sojourners. It deliberately ignores or marginalizes the major resident minority groups whose presence challenges the illusion of Japanese homogeneity. And in doing so, it also reinforces stereotyped images of Japan as a society characterized by a cultural 'purity' that needs defending against the malign forces of Anglo-Saxon global hegemony.

There are elements of this imagery in Shimauchi's discussion of 'discourses of colonialism' in Japan's approach to internationalization-through-English. Nonetheless, her paper pinpoints real issues, particularly relating to the way that the pursuit of global university rankings privileges work in English. An excessive focus on publishing in 'international' journals, for example, can lead to de-valuing fields (especially in the social sciences and humanities) that involve researching and writing about particular societies or cultures in the relevant languages (e.g. writing about Japanese history, culture, politics or sociology in Japanese).

However, as I noted above, we need to attend closely to questions of agency when generalizing about the nature or malign effects of 'Western' linguistic, cultural or academic hegemony. When it comes to university rankings, for example, it should be borne in mind that China played a pioneering role in establishing such rankings (the global universities 'league table' produced by Shanghai Jiaotong University 'league table' was the first such list) (see Vickers and Zeng 2017, Chapter 13). And different countries have responded to these international evaluative practices (whether university league tables or the OECD's PISA rankings) in quite different ways. It is Japanese policymakers, influenced by business leaders with an extremely narrow vision of education's purposes, who are responsible for defining 'internationalisation' almost exclusively in terms of mastery of English (even while failing to invest in the capacity to effectively teach it), and driving top universities to focus overwhelmingly on enhancing their global 'rankings'. European countries such as France and Germany have been far more resistant to defining 'success' for their universities in these terms.

Shimauchi's description of Japan as a 'non-postcolonial' country is meant to emphasize the relative autonomy of its higher education system vis-a-vis Western, especially Anglophone, academic traditions and institutions. But this characterization can be seen as double-edged, especially in the light of Tsuneyoshi's discussion of how 'internationalisation' discourse ignores precisely those countries and communities associated with the legacy of 
Japan's own brand of colonialism. The 'non-postcolonial' quality of Japanese society relates not only to the country's successful avoidance of Western colonial domination, but also to a failure to face up to and transcend its own history as a practitioner of colonialism in Asia. While Asian societies remain, as they have been since the 1980 s, key targets for the recruitment of international students into Japan's universities, those Asian students are seldom valued for their potential contribution to 'internationalising' the Japanese academic environment.

This relates to a central tension to which Shimauchi alludes directly, but which is also implicit in the other papers here: the symbiotic relationship between 'internationalisation' perceived as an instrument for raising national competitiveness, and increasingly extreme forms of nationalism. In other words, while intercultural understanding may be seen as an important goal by some grassroots practitioners, at national level the 'internationalisation' agenda is narrow and implicitly chauvinist. In official curricular documents, exchange and interaction with other cultures is often associated with the pursuit of peace (and the representation of Japan itself as supremely 'peace-loving'), and with the nurturing of economically useful global competencies, but diversity is seldom valued in and of itself. Instead, a certain paranoia emerges concerning the preservation of 'Japanese-ness', manifested in incessant exhortations to nurture students who will interact with foreigners and the outside world 'as Japanese' (nihonjin toshite) (see MGIEP 2017, chapter on East Asia).

The papers in the current issue thus highlight some serious contradictions in the way that educational 'internationalisation' is conceived and practiced in Japan today. But in identifying challenges for policy makers and educational scholars, they also indicate significant opportunities for re-shaping the theory and practice of 'internationalisation' in ways that might benefit Japan and the wider world. Put very simply, these relate firstly to the conceptualisation of identity and its implications for education, and secondly to ideas concerning the fundamental purpose of education itself.

As regards identity, Rappleye's impassioned plea for what amounts to a reinvention of 'Japanese-ness' can and should be extended and broadened. The worldwide rise of nationalism and populism threatens peace and security in ways that are only likely to be exacerbated by moves to erect defensive barricades against the foreign 'Other'. In this context, it is essential that articulating 'Japanese-ness' should mean not only resisting forces of neoliberal globalization, but also embracing a multi-faceted notion of what it means to be Japanese both domestically and internationally. Rather than exhorting youngsters to engage with their foreign counterparts or domestic minorities 'as Japanese,' it would be heartening to see curricula calling for them to interact with their closest neighbours 'as Asians' - and, through expanding provision for instruction in Asian languages, giving them the wherewithal to do so.

But sketching out a desirable path for educational internationalisation presupposes a certain ethical standpoint concerning not only Japan's identity as a nation, but also the aims of public education itself. Do schools and universities exist to serve 'the nation' according to a blueprint prescribed by ministerial satraps? Are pupils to be valued - and taught to value each other - primarily as units of productive capacity? Or should educational institutions see it as their mission not only, or even primarily, to promote technological innovation and enhanced production, but to foster critical reflection concerning the kind of society - local, national and global - that growth and innovation should serve? In an era of increasing automation, labour market instability and environmental and political crisis worldwide, answering these sorts of questions has become increasingly urgent - and impossible to achieve within 
the confines of national boundaries. The chance is there for Japan to take a lead in shifting global debate over such issues in a more sustainable direction.

\section{References}

MGIEP (2017). Rethinking Schooling for the 21st Century: the State of Education for Peace, Sustainable Development and Global Citizenship in Asia. New Delhi: UNESCO-MGIEP.

Vickers, Edward and Zeng, Xiaodong (2017). Education and Society in Post-Mao China. New York and London: Routledge. 